University of Nebraska - Lincoln

DigitalCommons@University of Nebraska - Lincoln

Publications, Agencies and Staff of the U.S.

Department of Commerce

U.S. Department of Commerce

2004

Use of Next Generation Weather Radar Data and Basin

Disaggregation to Improve Continuous Hydrograph Simulations

\author{
Ziya Zhang \\ National Weather Service \\ Victor Koren \\ National Weather Service \\ Michael Smith \\ National Weather Service \\ Seann Reed \\ National Weather Service \\ David Wang \\ National Weather Service
}

Follow this and additional works at: https://digitalcommons.unl.edu/usdeptcommercepub

Part of the Environmental Sciences Commons

Zhang, Ziya; Koren, Victor; Smith, Michael; Reed, Seann; and Wang, David, "Use of Next Generation Weather Radar Data and Basin Disaggregation to Improve Continuous Hydrograph Simulations" (2004). Publications, Agencies and Staff of the U.S. Department of Commerce. 56.

https://digitalcommons.unl.edu/usdeptcommercepub/56

This Article is brought to you for free and open access by the U.S. Department of Commerce at DigitalCommons@University of Nebraska - Lincoln. It has been accepted for inclusion in Publications, Agencies and Staff of the U.S. Department of Commerce by an authorized administrator of DigitalCommons@University of Nebraska - Lincoln. 


\title{
Use of Next Generation Weather Radar Data and Basin Disaggregation to Improve Continuous Hydrograph Simulations
}

\author{
Ziya Zhang ${ }^{1}$; Victor Koren²; Michael Smith³ ${ }^{3}$ Seann Reed"; and David Wang ${ }^{5}$
}

\begin{abstract}
Currently, the river forecasting system deployed in each of 13 River Forecast Centers of the National Weather Service primarily uses lumped parameter models to generate hydrologic simulations. With the deployment of the weather surveillance radar 1988 Doppler radars, more and more precipitation data with high spatial and temporal resolution have become available for hydrologic modeling. Hydrologists inside and outside the National Weather Service are now investigating how to effectively use these data to enhance river-forecasting capabilities. In this paper, six years of continuously simulated hydrographs from an eight-subbasin model are compared to those from a single-basin (or lumped) model, both applied to the Blue River basin $\left(1,232 \mathrm{~km}^{2}\right)$ in Oklahoma. The Sacramento soil moisture accounting model is used to generate runoff in all cases. Synthetic unit hydrographs for each subbasin convey the water to the outlet of the basin without explicit flow routing. Subdividing the basin into eight subbasins captures spatially variable rainfall reflected in the next generation weather radar products and produces improved results without greatly increasing the computational and data requirements. Strategies for calibrating the hydrologic model parameters for multiple subbasins are explored.
\end{abstract}

DOI: $10.1061 /(A S C E) 1084-0699(2004) 9: 2(103)$

CE Database subject headings: Hydrologic models; Aggregation; Simulation; Weather forecasting; Oklahoma; Hydrographs.

\section{Introduction}

One mission of the National Weather Service (NWS) is to provide river forecasts across the United States and its territories. Currently lumped hydrologic models are run for operational river forecasting at River Forecast Centers (RFCs). These lumped models are typically applied to basins ranging in size from 300 to $5,000 \mathrm{~km}^{2}$ using time steps of $6 \mathrm{~h}$ or longer. Lumped models are used because the data available from operational rain gauge networks will not support finer resolution modeling. With the establishment of the next generation weather radar (NEXRAD) program, weather surveillance radar 1988 Doppler (WSR-88D) radars have been deployed across the United States since 1991 (Heiss et al. 1990). Use of these radar data significantly increases the spatial and temporal resolution of precipitation inputs that are available for use in hydrologic models.

\footnotetext{
${ }^{1}$ Research Hydrologist, Hydrology Laboratory, National Weather Service, W/OHD1, 1325 East-West Highway, Silver Spring, MD 20910.

${ }^{2}$ Research Hydrologist, Hydrology Laboratory, National Weather Service, W/OHD1, 1325 East-West Highway, Silver Spring, MD 20910.

${ }^{3}$ Research Hydrologist and Project Leader, Hydrology Laboratory, National Weather Service, W/OHD1, 1325 East-West Highway, Silver Spring, MD 20910.

${ }^{4}$ Research Hydrologist, Hydrology Laboratory, National Weather Service, W/OHD1, 1325 East-West Highway, Silver Spring, MD 20910.

${ }^{5}$ Research Hydrologist, Hydrology Laboratory, National Weather Service, W/OHD1, 1325 East-West Highway, Silver Spring, MD 20910.

Note. Discussion open until August 1, 2004. Separate discussions must be submitted for individual papers. To extend the closing date by one month, a written request must be filed with the ASCE Managing Editor. The manuscript for this paper was submitted for review and possible publication on January 3, 2001; approved on April 20, 2003. This paper is part of the Journal of Hydrologic Engineering, Vol. 9, No. 2, March 1, 2004. CASCE, ISSN 1084-0699/2004/2-103-115/\$18.00.
}

This study investigates how gridded radar precipitation data can be used with existing NWS hydrologic models and software to improve simulations. The work described here is essentially an extension of the work described by Smith et al. (1999a). The basic idea is to include more basin disaggregation than is in normally done in NWS forecasting to see what benefits can be gained from capturing precipitation variability within a basin. The Smith et al. (1999a) studies considered distributed input but not spatially variable rainfall-runoff parameters. This study does consider spatially variable rainfall-runoff parameters. The characteristics of the basin studied here (Blue River above Blue, Oklahoma) are also quite different from the characteristics of basins studied by Smith et al. (1999a), leading to different conclusions.

Two important criteria in defining the modeling approach for this study were to use existing operational data and a continuous simulation model with well-defined calibration procedures. Although a large amount of research has been done in using radarbased precipitation products for hydrologic modeling, few of the research models satisfy both of these criteria. Many of the research models are event based. Specific references to several of these research efforts are provided in the next section. Also, by taking only a small step beyond existing NWS modeling procedures, the results of this work can be applied immediately in the field using current operational systems. Because we recognize that there are limitations to this approach, new grid-based modeling techniques that use explicit channel routing are also being developed and tested at the NWS Hydrology Laboratory (Reed et al. 2002)

One of our goals is to compare results from a discretized subbasin model to results from a lumped model of the type currently used in operations. The results of Smith et al. (1999a) and the research of others described below indicate that it is not universally true that use of higher-resolution precipitation data will lead 
to more accurate basin outlet hydrographs; it requires further testing.

\section{Literature Review}

Radar rainfall estimates have been widely used in hydrologic modeling (Pessoa et al. 1993; Mimikou and Baltas 1996; Peters and Easton 1996; Kull and Feldman 1998; Vieux and Bedient 1998; Winchell et al. 1998; Johnson et al. 1999; Koren et al. 1999; Smith et al. 1999a,b; Bedient et al. 2000; Carpenter and Georgakakos 2000; Yates et al. 2000).

Vieux and Bedient (1998) and Bedient et al. (2000) compared NEXRAD radar and rain gauge estimates to evaluate two reflectivity-rainfall rate relationships used in NEXRAD processing. Both precipitation estimates were used with a lumped model to generate event hydrographs for basins near Houston, Texas. For a limited number of events, it was found that the NEXRAD precipitation estimates lead to more accurate simulations compared to rain gauge forced simulations.

Peters and Easton (1996) applied the modified Clark (modClark) program, which adapts the Clark conceptual runoff model using translation and linear storage, to simulate several selected storm events for the Illinois River watershed above Tenkiller Lake in northeastern Oklahoma and northwestern Arkansas using radar data. The modified Puls method was used for channel routing of hydrographs from the upstream locations. Reasonable fit to observed flows was provided by the simulations under both spatially averaged radar-rainfall and grid-distributed rainfall data. The authors believed that a "substantial difference would occur between simulations based on grid-distributed versus spatially averaged rainfall" if a storm has marked spatial variability, as is the case for a localized convective storm. Kull and Feldman (1998) also demonstrated the ability of the modClark model to account for the spatially distributed nature of rainfall and runoff. Yates et al. (2000) combined radar-based quantitative precipitation estimates and forecasts to simulate a single event with a distributed model. Winchell et al. (1998) found that infiltration- and saturation-excess runoff mechanisms respond differently to uncertainty in radar estimates of precipitation.

Smith et al. (1999a) and others (Finnerty et al. 1997; Johnson et al. 1999; Koren et al. 1999) studied the hydrologic behavior and responses of several basins of the Illinois River above Tenkiller Ferry Lake (areas range from 285 to $2,483 \mathrm{~km}^{2}$ ) in Oklahoma using radar precipitation as input. Their studies include the sensitivity of the Sacramento soil moisture accounting (SACSMA) model to radar precipitation forcing at various spatial and temporal scales, comparisons of mean areal precipitation estimates from NEXRAD Stage III (MAPX) and mean areal precipitation estimates from rain gauge networks (MAP), numerical experiments on the sensitivity of runoff values to level of basin disaggregation, and small basin versus large basin modeling tests using the SAC-SMA model. The major conclusions from the work of Smith et al. (1999a) are the following: (1) use of radar precipitation estimates as input to lumped hydrologic models yields better results than the use of rain gauge data alone for the RFC basins studied; (2) basin disaggregation for the RFC basins studied showed limited improvement over the lumped approach; and (3) different statistical properties exist between achieved radar and gauged mean areal precipitation data, although the period for radar data analysis may not be long enough to have a meaningful comparison. Smith et al. (1999b) presented results from continuous multiyear simulations using radar precipitation data as input for single-basin lumped and subdivided basin models. The SAC-SMA model was applied in each subbasin using the same parameters, so their simulations incorporated only distributed rainfall input but not distributed parameters.

Stellman et al. (2000) used a method similar to that described by Smith et al. (1999a) to investigate streamflow simulations for the Flint River near Culloden, Georgia. The SAC-SMA model was applied using both MAP and MAPX as inputs. Their simulations from basin disaggregation and lumped modeling produced very similar results when MAP forcing was used. The MAPX data were found insufficient for modeling purposes due to underestimation compared to MAP data.

Carpenter and Georgakakos (2000) also used Stage III NEXRAD data to force a small basin hydrologic model (Georgakakos et al. 1996). In their work, the $4,150 \mathrm{~km}^{2}$ Illinois River basin is disaggregated into smaller subbasin units with areas ranging from tens of square kilometers to a few hundred square kilometers. The SAC-SMA model is applied to each subbasin. Selected peak events from 1993 to 1996 were simulated. The flow simulations at the outlet using basin subdivisions were comparable in accuracy to simulations from a lumped model. These results agree with those of Smith et al. (1999a).

Baltas and Mimikou (1997) compared lumped modeling results when both the MAP and MAPX (based on WSR-74 $S$-band weather radar and calibrated with rain gauge data) were used for a basin of $2,763 \mathrm{~km}^{2}$ area. It was found that the model performs better using radar combined with raingauge information than with raingauge information alone in both simulation and forecasting modes. They also applied a grid-based rainfall-runoff model to the Pyli basin located in central Greece $\left(135 \mathrm{~km}^{2}\right)$ and the results were compared to those derived by the lumped model using radar data (Baltas and Mimikou 1997). The grid model provided slightly better results. Their results and conclusions were obtained based on event simulations.

Johnson (1993) compared lumped and distributed simulations on Goodwin Creek, a $21 \mathrm{~km}^{2}$ basin located in northwestern Mississippi. Results from lumped and distributed simulations for several events were compared. The study was based on event simulations. The rainfall input was based on rain gauge data. His conclusion was that a distributed model performs better than a lumped model when there are accurate data describing soil and land use. If there are sufficient subbasin stream gauge data for calibration, then lumped simulations are comparable to distributed simulations. Since Johnson's study was done on a much smaller scale than the basin scales discussed in this paper, the conclusions he made are not necessarily transferable to larger scale simulations.

As has been shown in a few studies, the use of radar-derived precipitation data can improve modeling accuracy. Most studies in which radar-derived precipitation data are used are conducted separately without comparing the differences between different approaches (as lumped versus distributed or lumped versus disaggregated). There are relatively few studies that directly compare lumped and distributed simulations using radar data (Pessoa et al. 1993; Mimikou and Baltas 1996; Baltas and Mimikou 1997; Smith et al. 1999b; Stellman et al. 2000), and most efforts have been concentrated on event-based analysis where initial conditions before the event are assumed or need to be adjusted. Further studies are needed to define the performance differences between lumped models and distributed or discretized models and the conditions under which one simulation mode is better than the other. 


\section{Model Description and Parameter Determination}

The Sacramento soil moisture accounting model (Burnash et al. 1973; World Meteorological Organization (WMO) 1975, 1983) is one of the most common models used to simulate water balances and river flows at the RFCs (Peck 1976). It is calibrated based on multiyear time series of observed discharge and basin average precipitation.

The SAC-SMA model is a conceptual model that incorporates a two-layer soil structure (upper zone and lower zone) as its basic design. Each layer is treated as a reservoir containing both tension water and free water components that interact to generate soil moisture states. Runoff consists of five components depending on the soil moisture conditions. The free water storage in the lower zone is divided into primary and supplemental storage components from which slow and fast base flow are generated, respectively. Rainfall contributes to the processes of surface runoff and percolation from the upper zone to the lower zone storage. The partitioning depends on tension water and free water storage available in the upper zone. Excess rainfall exists when the content of the upper zone tension water storage exceeds the upper zone tension water maximum UZTWM. When the rainfall excess exceeds the upper zone free water capacity UZFWM, it becomes surface runoff. When the upper zone storages are filled, the runoff rate will depend on lower zone tension water LZTWM, lower zone free water capacities LZFSM and LZFPM, and their deficiencies. The runoff rate generated from each reservoir is dependent upon its depletion coefficient, namely, UZK for upper zone interflow, LZSK for lower zone supplemental base flow, and LZPK for lower zone primary base flow. Percolation from the upper zone to the lower zone depends on the upper zone free water content and the deficiency of lower zone moisture volume. Two parameters, the maximum rate of percolation ZPERC and an exponent value REXP also control the percolation function. Percolated water is used first to satisfy any tension water deficit in the lower zone. The remaining amounts of percolated water are then used to recharge the lower zone primary and supplemental free water storages. A constant fraction of percolated water PFREE bypasses the lower zone tension water to directly recharge the primary and supplemental free water storages. There are also five additional parameters in the model to control runoff from impermeable areas and water losses from evapotranspiration. Estimates of monthly potential evapotranspiration (ET demand) are also required by the SAC-SMA model. First, monthly and annual estimates of free water surface evaporation (PE) are derived from observed pan data and climatic means (NWS 1982). Twelve monthly adjustment factors are derived to modify the PE values for the effect of vegetation.

Although the 16 parameters in the SAC-SMA model have physical meanings, they cannot be measured directly. When applied to a selected basin, the SAC-SMA model parameters must be calibrated using historical hydrometeorological data. For ungauged basins or subbasins where observed discharges are not available, it is difficult to estimate the model parameters. Calibration usually requires at least eight years of observed precipitation and discharge data (University of Arizona 1995). About the same amount of data are recommended for model verification. Koren et al. (2000) developed a set of analytical relationships to derive 11 of 16 initial SAC-SMA model parameter values based on Soil Conservation Service (SCS) (now Natural Resources Conservation Service) curve number, soil texture, and soil depth. These parameter estimates can be readily derived from nationally available databases. Miller and White (1998), for example, have processed the USDA State Soil Geographic Database (STATSGO) to

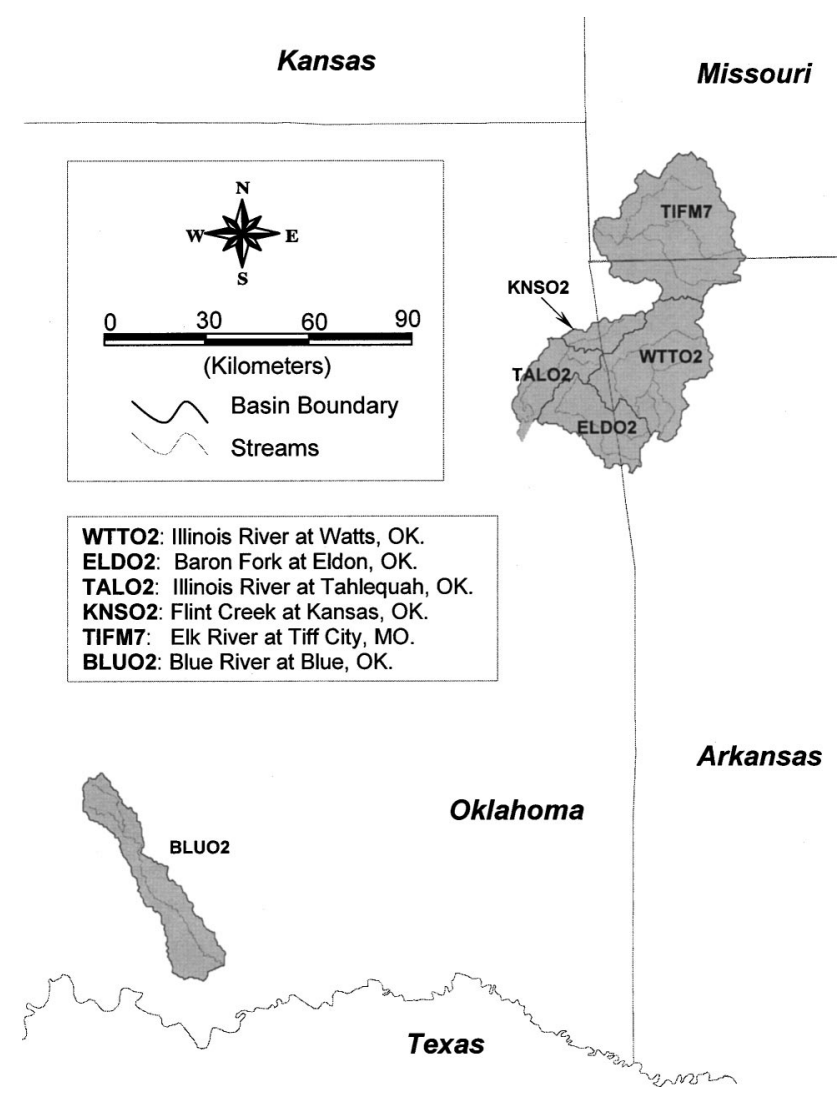

Fig. 1. Location map of Blue River basin and basins studied by Smith et al.(1999a) within ABRFC

produce national soil parameter grids that are more accessible to the modeling community. Initial parameters estimated from soil data are used here to describe the spatial variability of parameters. However, adjustments to these initial values are needed to remove simulation biases.

Unit hydrographs are used with the SAC-SMA model to convert runoff depths to discharge at the basin outlet. There is no explicit channel routing algorithm to route water from each subbasin to the basin outlet. Instead, an implicit unit-hydrographbased approach that utilizes a linear system concept was adopted. Because of this linearity assumption, an outlet hydrograph can be constructed as a summation of subbasin hydrographs routed to the basin outlet

$$
Q(t)=\sum_{i=1}^{N} \int_{0}^{t} q_{i}(\zeta) \rho_{i}\left(t-\zeta, \tau_{i}\right) d \zeta
$$

where $q_{i}(t)=$ lumped inflow to the $i$ th subbasin; and $\rho_{i}\left(t, \tau_{i}\right)$ $=$ total unit hydrograph of the $i$ th subbasin. The parameter $\tau_{i}$ depends on the subbasin lag time $\tau_{i, s}$ and the downstream channel lag time $\tau_{i, c}$.

The total subbasin unit hydrograph is a convolution of a local subbasin unit hydrograph $\rho_{i, s}\left(t, \tau_{i, s}\right)$ and a downstream channel unit hydrograph $\rho_{i, c}\left(t, \tau_{i, c}\right)$ :

$$
\rho_{i}\left(t, \tau_{i}\right)=\int_{0}^{t} \rho_{i, s}\left(\zeta, \tau_{i, s}\right) \rho_{i, c}\left(t-\zeta, \tau_{i, c}\right) d \zeta
$$

Clark's approach (Clark 1945) can be used to estimate $\rho_{i, s}\left(t, \tau_{i, s}\right)$ from digital elevation model (DEM) data, and Nash's cascade model (Rosso 1989) can be used for a downstream channel unit hydrograph. In practical applications with limited flow 


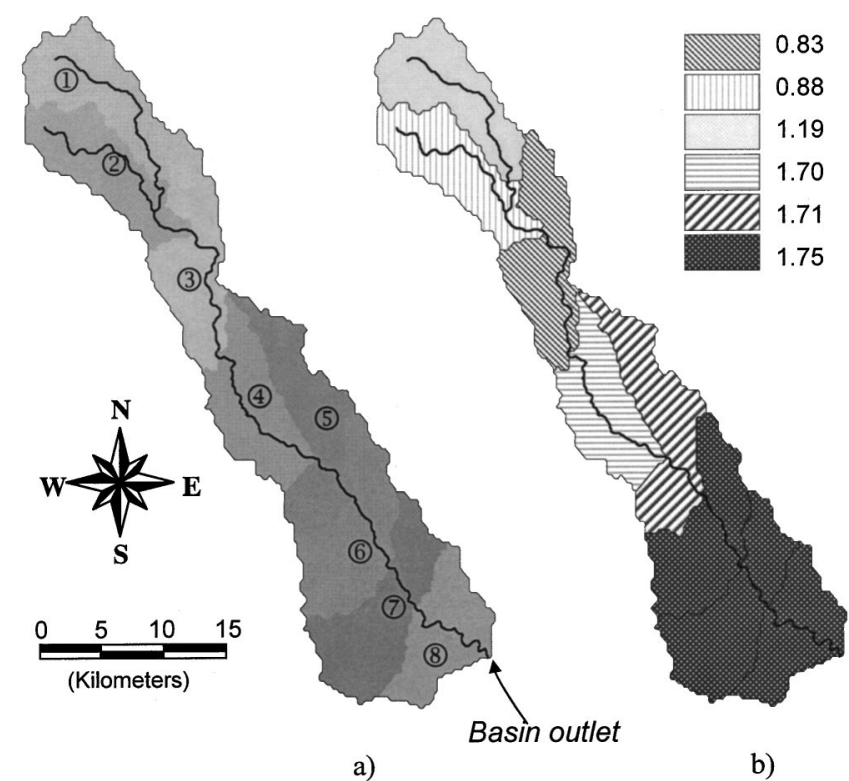

Fig. 2. (a) Blue River basin and its subbasins; (b) average soil depth for each subbasin

measurement data, it may be easier to estimate the total subbasin unit hydrograph directly (without breaking it into the two terms shown above) using DEM data and calibration techniques.

\section{Study Area}

In this study we disaggregate the Blue River basin (Fig. 1) near Blue, Oklahoma into eight subbasins. The Blue River basin is long and narrow with a drainage area of $1,227 \mathrm{~km}^{2}$. Subbasin divisions and soil depths are shown in Fig. 2 and subbasin areas are listed in Table 1. Examining the normalized stream flow of Blue River together with those of several other basins (shown in Fig. 1) within the domain of the Arkansas Red Basin River Forecast Center (ABRFC) reveals that the Blue River basin has distinguishable rainfall-runoff behavior as shown in Fig. 3. From the hydrograph comparison shown in Fig. 3, the Blue River has a much faster recession rate than the basins studied by Smith et al. (1999a). The soil depth distribution of the Blue River basin (from STATSGO) is more variable (from 0.8 to $1.8 \mathrm{~m}$ ) than the five Illinois River basins (range from 1.0 to $1.6 \mathrm{~m}$ with most values around $1.5 \mathrm{~m}$ ) studied by Smith et al. (1999a). When the basin is disaggregated into eight subbasins, the averaged soil depth for each subbasin varies from 0.83 to $1.75 \mathrm{~m}$ [Table 1 and Fig. 2(b)]. Soil depth is one indicator of how soil properties vary within the basin. The conceptual upper and lower zone storages in the SACSMA model are related to soil texture, soil depth, and soil hydraulic properties. The partitioning of the soil profile depth into these layers was achieved using curve number and soil texture information and the methods of Koren et al. (2000).

Hourly Stage-III radar precipitation data are available for this region from 1993 to 1999 . Hourly observed discharge data at the
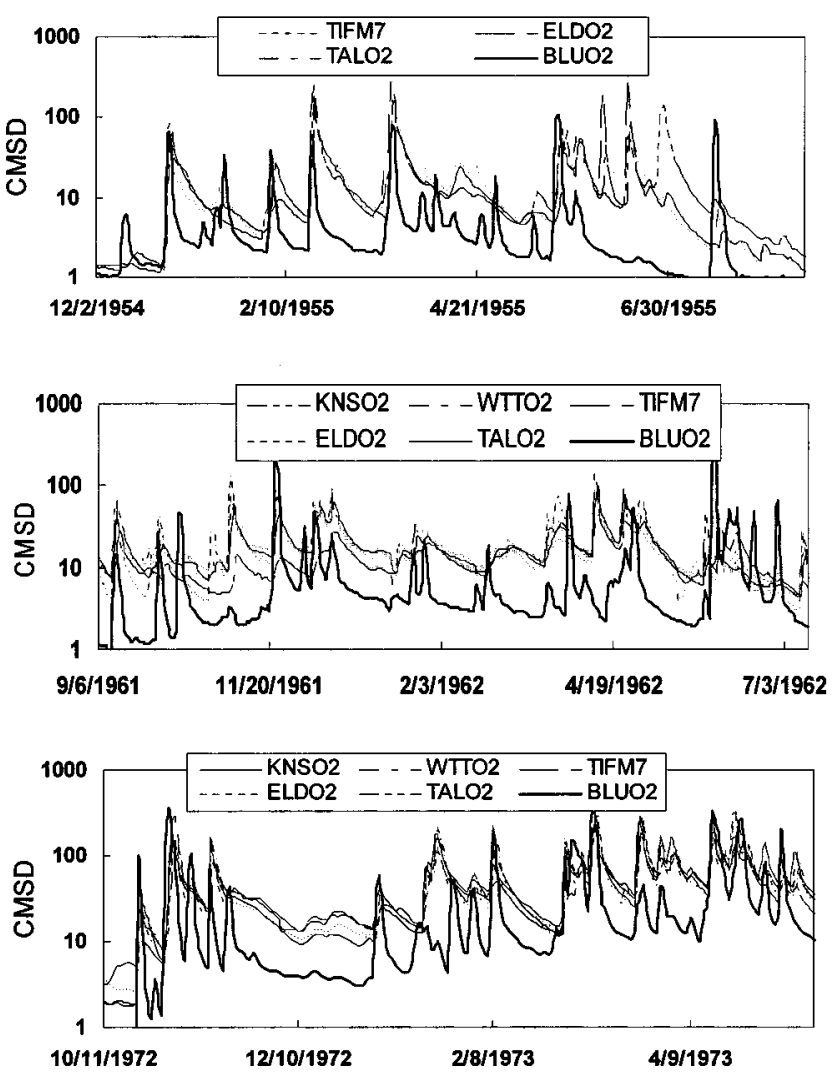

Fig. 3. Hydrograph comparison between Blue River basin and other basins within ABRFC

outlet were obtained from the USGS. There were no measured discharges at any location above the selected outlet near Blue.

\section{Experiments and Results}

\section{Lumped Simulation}

A lumped simulation using a single set of SAC-SMA parameters for the entire Blue River basin is studied first. The hourly MAPX time series were used as input forcing. Since there are about six years of hourly radar precipitation data available for Blue River basin, the whole period of data was used for the SAC-SMA model calibration. A manual calibration strategy was used to derive final values of SAC-SMA parameters and monthly PE demand values. Basin average total runoff was routed to the outlet using a basin unit hydrograph. The simulation result is a continuous hourly discharge time series from the summer of 1993 to the spring of 1999. It should be noted that the lumped retrospective simulations presented here are not necessarily representative of the quality of river forecasts generated at the NWS ABRFC. River forecasts for public use include the expertise of NWS personnel who analyze real time meteorological and hydrological inputs and conditions and make modifications to inputs or model states as appropriate.

Table 1. Soil Depths and Areas for Subbasins of the Blue River Basin

\begin{tabular}{lcccccccrrr}
\hline Subbasin & 1 & 2 & 3 & 4 & 5 & 6 & 7 & 8 & Mean \\
\hline Depth $(\mathrm{m})$ & 1.19 & 0.88 & 0.83 & 1.7 & 1.71 & 1.75 & 1.75 & 1.75 & 1.45 & 129 \\
Area $\left(\mathrm{km}^{2}\right)$ & 153 & 150 & 153 & 144 & 163 & 165 & 170 & 153 & Total=1,227 \\
\hline
\end{tabular}




\section{Multiple Subbasin Modeling}

The SAC-SMA model is applied to each of the subbasins shown in Fig. 2(a). Software was developed to disaggregate the basin into a number of desired subbasins depending on a predefined subbasin threshold area (Smith et al. 1999a). The optimal number of basin subdivisions is not obvious at the outset. The principle followed here is to make each subbasin's area relatively equal and minimize the flow exchange between subbasins because there is no mechanism to account for lateral mass exchanges between them except flow from channels. If possible, the disaggregation should also account for the variation of soil properties and land cover such that the properties within each subbasin are as uniform as possible and the averaged runoff response can be adequately predicted. However, the storm cell size is also a factor that needs to be considered, although one still cannot make sure this would satisfy the condition of uniformity of rainfall for a specific event. There must be a balance between the number of subbasins and the uniformity of physical characteristics within them. With more subbasins, there is more work in setup and calibration; however, the uniformity assumption within each subbasin becomes more valid.

When the SAC-SMA model is applied to each subbasin, the simulated total flow at the basin outlet is the sum of each subbasin's runoff routed to the outlet using its unit hydrograph. The information about channel length to the outlet and other characteristics for each subbasin has been considered implicitly in the unit hydrograph [described in Eqs. (1) and (2)] based on DEM data and some calibration effort. There is no explicit channel routing from each subbasin to the outlet. Total simulated discharge is compared to the observed discharge at the outlet.

Compared to the lumped approach, calibration of the subbasin parameters is a more complicated process. For the Blue River basin, it is difficult to derive parameters for each subbasin through analysis of observed historical flow and precipitation data due to the lack of internal observed discharge information. In this research, the technique developed by Koren et al. (2000) is used to estimate initial SAC-SMA parameter values for each subbasin. The Clark approach (Clark 1945) is used to derive unit hydrographs for the lumped basin and the eight subbasins. Unit hydrographs for the eight subbasins are used to transform runoff volume into discharge and route the discharges to the basin outlet. It should be pointed out that unit hydrographs for the lumped parent basin and the eight subbasins were derived independently, so it is not necessarily true that the unit hydrograph for the lumped case shown in Fig. 4 is equal to the summation of those of the eight subbasins. Manual calibration then continues based on these initial parameter estimates (independently calibrated). Only slight changes (time to peak for a couple of subbasins) were made for unit hydrographs during the manual calibration. A comparison of the unit hydrographs is shown in Fig. 4. Manual calibration with the subbasin modeling approach requires the analysis of individual storms in which the rainfall distribution is nonuniform. An example of this calibration approach is discussed in the context of the results given later in this paper. Due to low spatial variability, it was assumed that the same ET demand values derived during the lumped calibration are appropriate for each subbasin.

\section{Results}

Both lumped and subbasin simulations were run continuously from 1993 to 1999. The continuous hydrograph time series for the lumped basin and each subbasin are output for analysis. Percent bias, absolute percent bias, and a correlation coefficient were

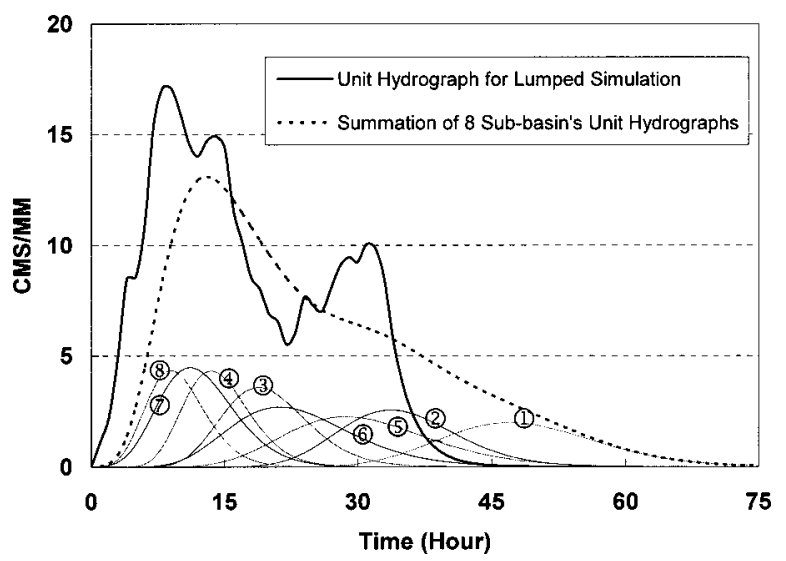

Fig. 4. Demonstration of unit hydrograph and time-to-peak differences between subbasins of the Blue River basin

computed on an event, monthly, and annual basis. Event statistics were also computed for different flow intervals. The percent bias is defined as

$$
\operatorname{Bias}(\%)=\frac{\sum_{i=1}^{N}\left(S_{i}-O_{i}\right)}{\sum_{i=1}^{N} O_{i}}(100)
$$

where $S_{i}=$ hourly simulated value; $O_{i}=$ hourly observed value; and $N=$ number of values. The percent bias represents an overall volume comparison between two samples and is one of the major statistics used to guide manual calibration (Smith et al. 2002). Due to the cancellation of positive and negative values during the summation, this index may not reflect the hydrograph fit comparison between simulated and observed data. A small value of percent bias cold exist for an event but the hydrograph comparison may be far apart. Therefore, the mean absolute error (MAE) as shown in Eq. (4) is also considered to evaluate simulations

$$
\operatorname{MAE}(\%)=\frac{\sum_{i=1}^{N}\left|S_{i}-O_{i}\right|}{\sum_{i=1}^{N} O_{i}}(100)
$$

The correlation coefficient for hourly flows, $R$, is also determined for different comparisons. It is calculated as

$$
R=\frac{N \cdot \sum_{i=1}^{N} S_{i} O_{i}-\sum_{i=1}^{N} S_{i} \cdot \sum_{i=1}^{N} O_{i}}{\left\{\left[N \cdot \sum_{i=1}^{N} S_{i}^{2}-\left(\sum_{i=1}^{N} S_{i}\right)^{2}\right]\left[N \cdot \sum_{i=1}^{N} O_{i}^{2}-\left(\sum_{i=1}^{N} O_{i}\right)^{2}\right]\right\}^{0.5}}
$$

Table 2 shows the yearly percent bias, mean absolute error, and correlation coefficient statistics of the subbasin and lumped simulations for the Blue River basin from 1994 to 1999. Results

Table 2. Yearly Percent Bias, Mean Absolute Error, and Correlation Coefficient Comparison between Eight-Subbasin and Lumped Simulations for the Blue River Basin

\begin{tabular}{lcccccccc}
\hline & \multicolumn{3}{c}{ Eight subbasins } & & \multicolumn{3}{c}{ Single basin } \\
\cline { 2 - 3 } Year & Bias $(\%)$ & MAE $(\%)$ & $R$ & & Bias $(\%)$ & MAE $(\%)$ & $R$ \\
\hline 1994 & -31 & 45 & 0.86 & & -31 & 46 & 0.87 \\
1995 & -44 & 46 & 0.92 & & -38 & 45 & 0.86 \\
1996 & -15 & 37 & 0.90 & & -14 & 44 & 0.88 \\
1997 & 23 & 41 & 0.92 & & 23 & 46 & 0.87 \\
1998 & 18 & 31 & 0.95 & & 26 & 43 & 0.94 \\
1999 & 18 & 53 & 0.76 & & 7 & 59 & 0.56 \\
Average & -5 & 42 & 0.89 & & -5 & 47 & 0.83 \\
\hline
\end{tabular}



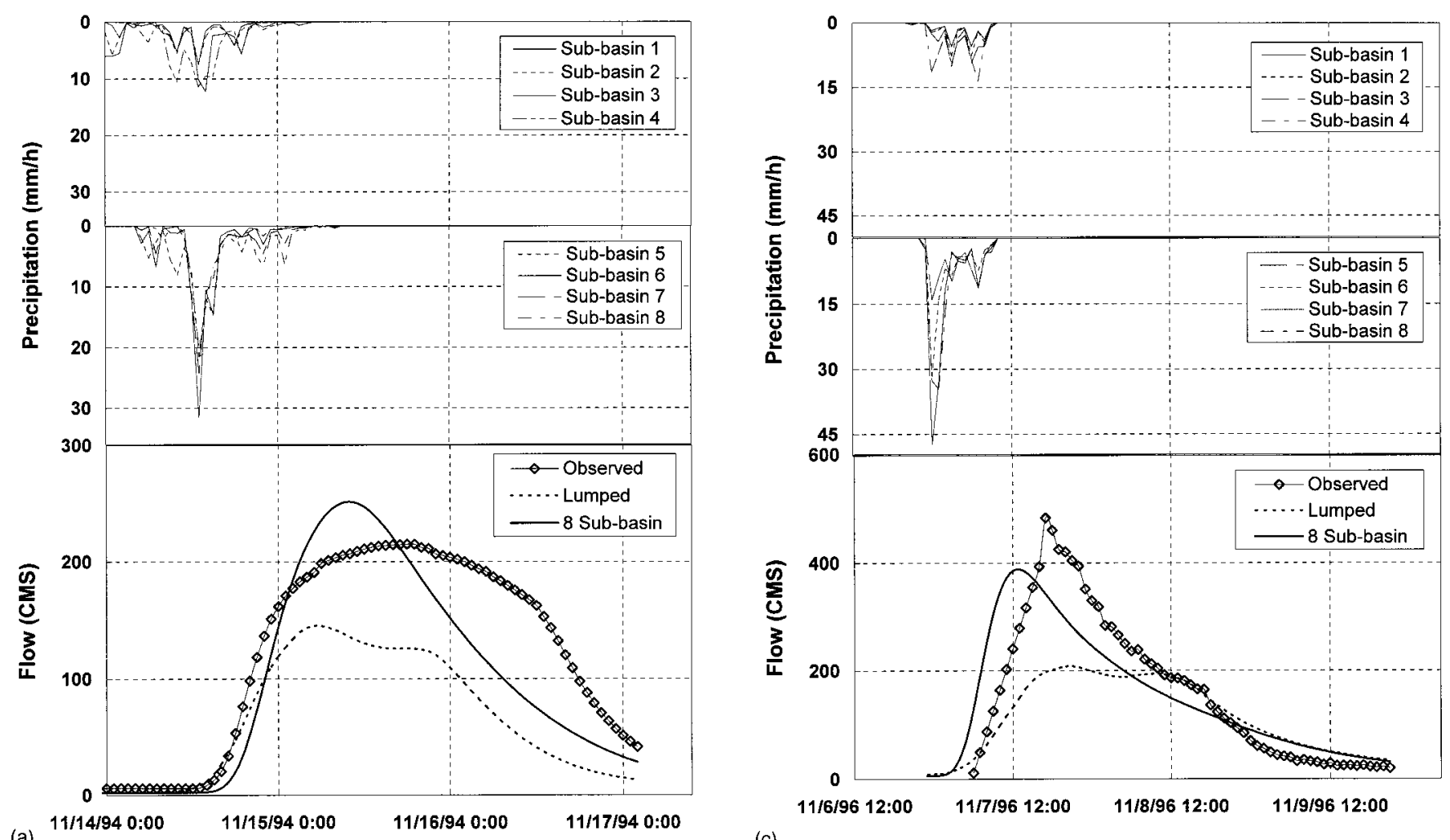

(a)

(c)
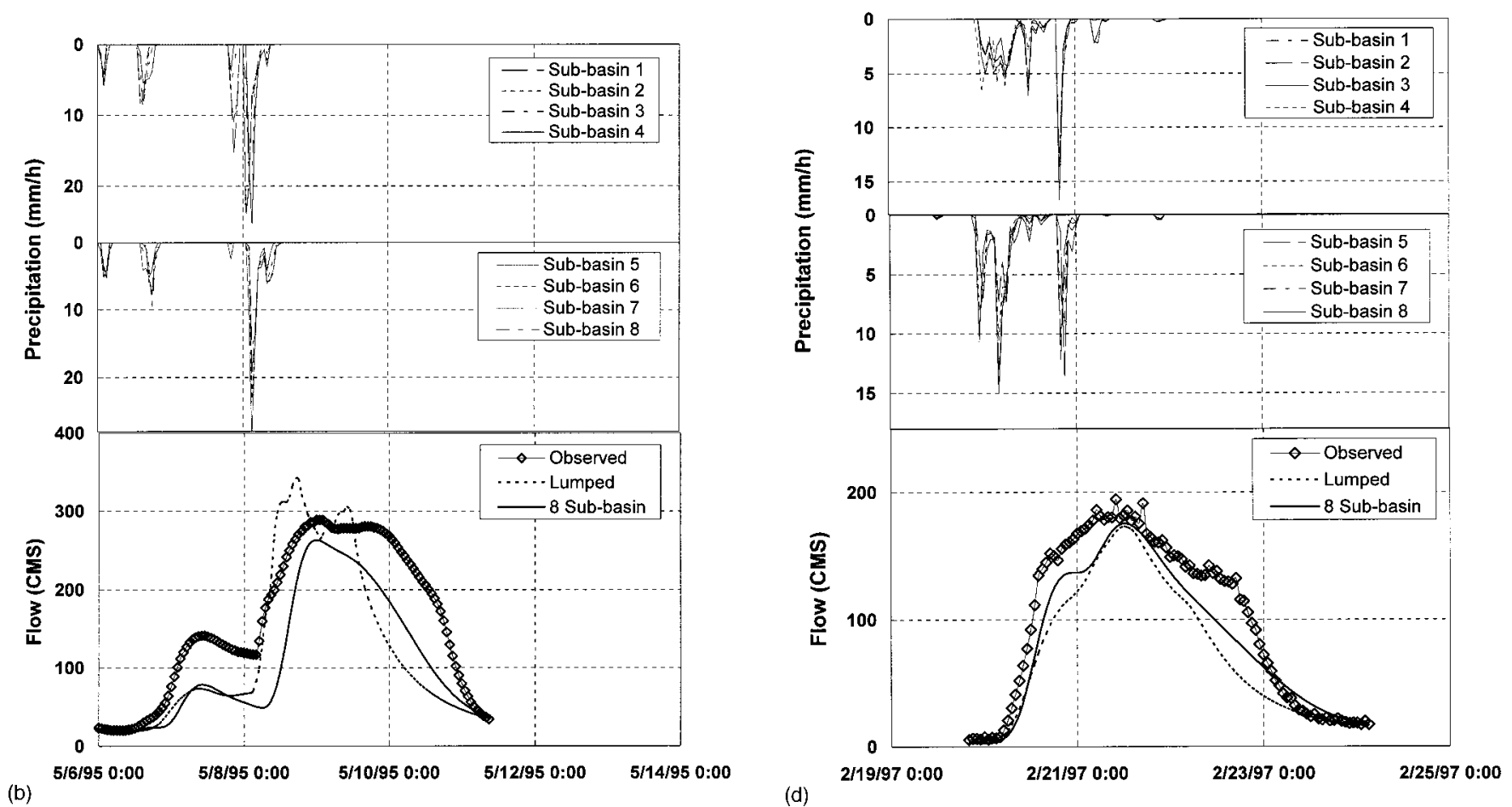

Fig. 5. Simulated and observed hydrographs and subbasin precipitation for an event in (a) 1994; (b) 1995; (c) 1996; (d) 1997; (e) 1998; and (f) 1999.

for 1993 are not presented because the simulations only began in May, and the short period is likely to be dominated by errors in initial conditions. Although the percent bias for each year is close between the lumped and eight subbasin simulations, the mean absolute error and correlation coefficient for the semidistributed cases are consistently better than for the lumped cases. This means that the overall annual runoff volumes between the two are more or less the same, but the hydrograph fit to the observed data for the eight-subbasin simulation is better than the lumped simulation. Notice that the percent bias statistics for 1994-1996 are negative while the statistics for 1997-1999 are positive, which is consistent with the analysis by Wang et al. (2000) showing a temporal shift in the consistency of the radar data relative to gaugeonly estimates. 


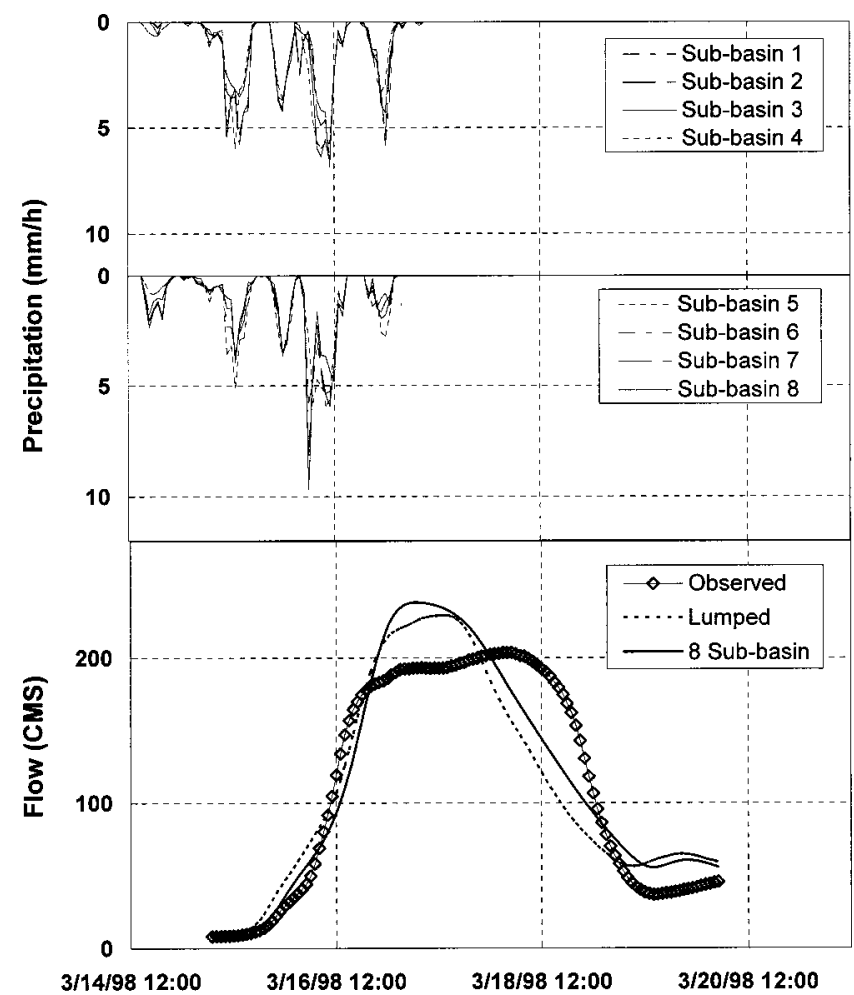

(e)

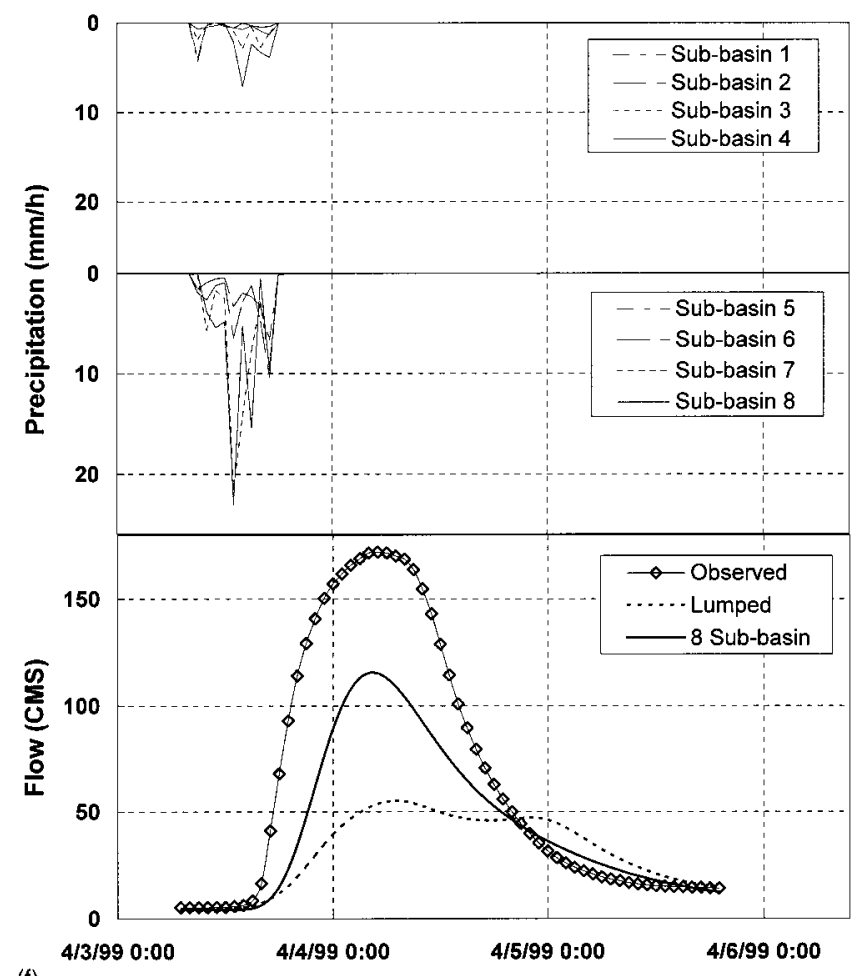

(f)

Fig. 5. (Continued)

Hydrograph plots for several large events (one from each year) are shown in Figs. 5(a)-5(f) and their corresponding statistics are shown in Table 3. The percent biases based on absolute differences for all events in the eight-subbasin simulation (versus observed hydrograph) are all better than those from the lumped results (Lmp). This means that the subbasin simulation (Dst) more closely fits the observed data than does the lumped simulation.
With one exception [1996 event shown in Fig. 5(c)], comparison of the correlation coefficients in Table 3 supports this conclusion. In Fig. 5(c), the eight-subbasin hydrograph has much better peak flow values and overall shape than the single-basin lumped hydrograph. So this exception is caused by the timing offset between the observed hydrograph and the semidistributed simulated hydrograph. Peak flow errors and improvement of peak flow are also included in Table 3. The peak flow errors were calculated by comparing simulated peaks to observed peaks. The peak flow improvements [Impr (\%), expressed as percent of (Error $_{\mathrm{Lmp}}$ - Error $\left._{\text {Dst }}\right) /$ Error $\left._{\text {Lmp }}\right]$ were evaluated by directly comparing the peak flow errors of subbasin simulations to lumped cases. In five out of the six largest events, peak flow predictions from the subbasin simulations were better than those from the lumped simulations.

As might be expected, the differences between the eightsubbasin and lumped simulations seem to be related to the precipitation distribution over the basin. To illustrate the effect of rainfall spatial distribution on the simulated results from both the subbasin and lumped methods, three representative cases are chosen with hydrographs shown in Figs. 6(a)-6(c). Their statistics are presented in Table 4 . The rainfall pattern for each event is different. The correlation coefficients for cases having spatially variable rainfall distributions are much better in eight-subbasin mode than those in lumped mode. For the case where rainfall is relatively uniform, the eight-subbasin and lumped simulations are statistically very similar.

In Figs. 6(a)-6(c), in addition to showing basin outlet hydrographs, precipitation time series for each subbasin and simulated individual discharge time series for each subbasin are also shown. For the event of June 1997 [Fig. 6(b)], the simulated discharge in the eight-subbasin simulation shows better agreement than the lumped simulation. Looking at the precipitation distribution for this event [Fig. 6(b)], subbasins 7 and 8 have the most intense rainfall during this period. As seen in Fig. 2, these two subbasins are close to the basin outlet; therefore they should have faster responses to rainfall than the other subbasins. As a result, the discharges at the outlet for this event are mostly from direct surface runoff from subbasins 7 and 8 . As seen in the subbasin hydrographs in Fig. 6(b), other subbasin contributions to flow at the outlet are mainly delayed base flows. In the single-basin lumped simulation, the precipitation forcing is the result of averaging grid-based radar data over the basin. The direct consequence of lumping the radar rainfall estimates is ignoring the spatial variations of precipitation and reducing the rainfall intensity at local areas. In this case, the rainfall intensity on subbasins 7 and 8 is reduced while it is increased for the upper subbasins that have longer travel time to the outlet. Thus, it is understandable why the hydrograph from the lumped simulation is lower and flatter than the one for the eight-subbasin case. This is also true for the large events shown in Figs. 5(a), 5(c), and 5(f).

For the event of June 1998 [Fig. 6(c)], the hydrograph from the lumped simulation is much greater than hat from the eightsubbasin simulation. High rainfall intensities were concentrated over subbasins 2 and 3, while lesser amounts fell on the remaining subbasins. In the lumped approach, spatial averaging shifts some of the rainfall from upper subbasins to lower subbasins, resulting in more rainfall for those fast response subbasins. This causes the hydrograph from the lumped simulation to be greater in magnitude than the hydrograph from the eight-subbasin simulation [which is also the case for the large event shown in Fig. 5(b)]. The multipeaked hydrograph of the June 1998 event is well simulated in the eight-subbasin mode (one can tell from the cor- 
Table 3. Percent Bias, Mean Absolute Error, Correlation Coefficient, Peak Flow Error, and Peak Flow Improvement for the Subbasin and Single-Basin Simulations for Major Events from 1994 to 1999

\begin{tabular}{|c|c|c|c|c|c|c|c|c|c|c|}
\hline \multirow{3}{*}{\multicolumn{2}{|c|}{ Event }} & \multirow{2}{*}{\multicolumn{3}{|c|}{ Eight subbasins semidistributed }} & \multirow{2}{*}{\multicolumn{3}{|c|}{ Single basin lumped }} & \multicolumn{3}{|c|}{ Peak flow } \\
\hline & & & & & & & & Error & & \\
\hline & & \multirow{2}{*}{$\frac{\operatorname{Bias}(\%)}{-18}$} & \multirow{2}{*}{$\frac{\text { MAE }(\%)}{28}$} & \multirow{2}{*}{$\frac{R}{0.91}$} & \multirow{2}{*}{$\frac{\text { Bias }(\%)}{-46}$} & \multirow{2}{*}{$\frac{\text { MAE }(\%)}{47}$} & \multirow{2}{*}{$\frac{R}{0.90}$} & \multirow{2}{*}{$\frac{\text { Distributed }}{17}$} & \multirow{2}{*}{$\frac{\text { Lumped }}{32}$} & \multirow{2}{*}{$\frac{\text { Improvement }(\%)}{46}$} \\
\hline $\mathrm{a}$ & 21:00 11/13/94 6:00 11/17/94 & & & & & & & & & \\
\hline $\mathrm{b}$ & 23:00 5/5/95 11:00 5/11/95 & -32 & 32 & 0.93 & -24 & 34 & 0.83 & 9 & 19 & 52 \\
\hline $\mathrm{c}$ & 22:00 11/6/96 8:00 11/10/96 & -0.2 & 34 & 0.86 & -23 & 37 & 0.90 & 20 & 57 & 65 \\
\hline $\mathrm{d}$ & 19:00 2/19/97 4:00 2/24/97 & -15 & 18 & 0.98 & -26 & 26 & 0.96 & 8 & 10 & 20 \\
\hline $\mathrm{e}$ & 6:00 3/15/98 6:00 3/20/98 & 2 & 19 & 0.94 & -1 & 23 & 0.90 & 17 & 13 & -30 \\
\hline $\mathrm{f}$ & 7:00 4/3/99 19:00 4/5/99 & -34 & 37 & 0.94 & -53 & 62 & 0.68 & 33 & 68 & 52 \\
\hline
\end{tabular}

relation coefficient comparison). The first peak was mainly produced by flow from subbasin 8 , whereas the second peak came mainly from subbasin 2 . This again shows that a basin disaggregation approach can greatly improve the flow results when there is a large variation of precipitation distribution.

For the event of November 1996 [Fig. 6(a)], the precipitation distribution is more uniform. The simulated hydrographs from the eight-subbasin and single-basin modes are quite similar and both have high correlation coefficients relative to the observed data. Contributions to the outlet during this event come from all subbasins, with the responses from subbasins 8 and 7 being earlier and higher than those of the rest of subbasins. The large event in 1998 [Fig. 5(e)] shows a similar result.

\section{Relative Importance of Including Spatial Rainfall Variability and Parameter Variability}

Comparisons of single-basin and eight-subbasin simulations presented above have shown that for the Blue River basin simulations with the basin disaggregation approach outperform those from the single-basin approach. This conclusion was not clearly confirmed in previous studies on several other basins within the domain of ABRFC (Smith et al. 1999a, b). However, there are two major differences between this study and the study conducted by Smith et al. (1999a, b). The first difference is basin shape. The Blue River basin is long, narrow, and orthogonal to typical storm directions, whereas the others shown in Fig. 1 are relatively round in shape. For this reason, it is anticipated that the Blue River basin is more sensitive to spatial variation of precipitation input and the basin's physical characteristics. The second difference is that the variation of soil properties between subbasins is considered in this study. Differences in soil properties such as soil depth exist between subbasins, and thus the SAC-SMA parameters derived for these subbasins are also different. The average soil depth within the Blue River basin [Fig. 2(b)] has more variation between subbasins than that of other basins studied by Smith et al. (1999a). Therefore, assigning variable parameter values among subbasins of the Blue River basin may have more effect on the basin's runoff response than in the other basins shown in Fig. 1. Determining the relative importance of basin shape and spatially varying parameters requires further study.

Two tests (described in Table 5) on the Blue River basin are designed to determine the effect of individual factors on the simulation results. Test 1 is designed to determine the effect of basin shape on simulations. The idea is to eliminate the shape effect while keeping other characteristics the same as in the eightsubbasin semidistributed simulation. In order to isolate the shape factor and its effect on the travel time to the outlet, the unit hydrograph from the lumped calibration (adjusted by the subba- sin's area) is used for each subbasin, while rainfall-runoff parameters for each subbasin are kept the same as in the eight-subbasin calibration. In this case, the time to peak for each subbasin is identical, and the spatial distribution of the generated runoffs from subbasins were ignored. Consequently, the simulation difference between this test and the distributed test is caused by excluding only the basin shape factor. Any improvement in simulation results from this test over the lumped simulation is attributed to the variability of soil properties and precipitation.

The second test is designed to isolate the effect of soil properties. In this case, it is assumed that the soil depth and other properties are uniform across all subbasins. The parameters from the single-basin lumped calibration are used as initial values. They are then adjusted uniformly up or down during further calibration. The differences between the simulation results from this test and the case with variable parameters show the effects of excluding model parameter variations. Any improvement of simulation results from this test over the single-basin lumped simulation is attributed to subbasin location differences (basin shape factor) in the inherent consideration of precipitation variability. In these two tests, the MAPX time series for each subbasin are used. The comparisons of test results together with those from previously described single-basin lumped and eight-subbasin simulations are shown in Tables 6, 7, and 8.

Hydrographs for these two new tests together with the results from lumped and eight-subbasin simulations are plotted in Figs. 7(a) -7 (f) and 8(a)-8(c). For most of the cases presented above, hydrographs and peak flow errors for the two tests fall between the eight-subbasin and lumped cases. Based on these tests, when rainfall distribution is considered in the simulation, both basin shape factor (difference between Test 1 and the semidistributed simulation) and soil property variation between subbasins (difference between Test 2 and the eight-subbasin simulation) affect the model simulation results. Table 8 shows that these effects increase dramatically when the rainfall pattern is highly variable. Comparing the annual absolute percent bias and correlation coefficient (in Table 6) and peak flow error for different events (in Table 7) between the two tests, Test 2 has slightly better simulation results than Test 1 (in four out of six cases shown in Table 6 and five out of six cases shown in Table 7). This suggests that the effect of basin shape is more significant than variation in soil properties in the test basin. As shown in Fig. 4, the time-to-peak differences among subbasins of the Blue River basin are obvious. So it makes sense that the shape factor has a large effect on the runoff response in the Blue River. It is also evident in this example that accounting for both rainfall distribution and soil property variation contributes to the improvement of model simulation results. 


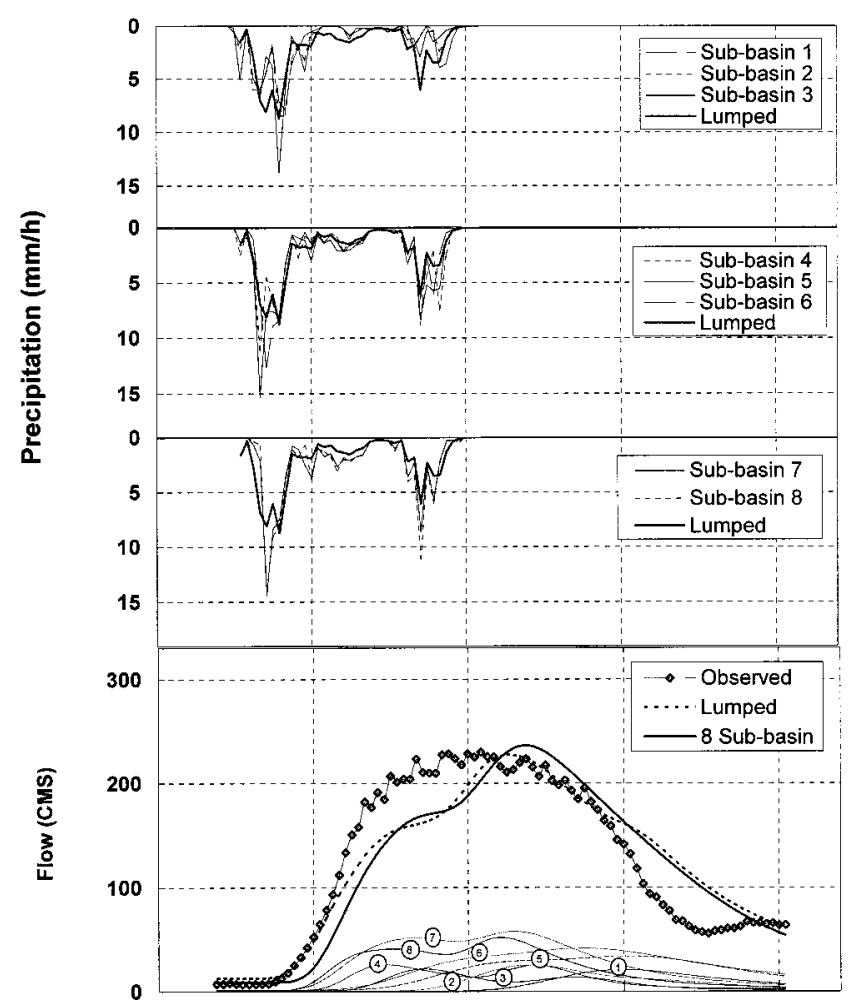

(a) $11 / 23 / 9612: 00 \quad 11 / 24 / 9612: 00 \quad 11 / 25 / 96$ 12:00 11/26/96 12:00 11/27/96 12:00

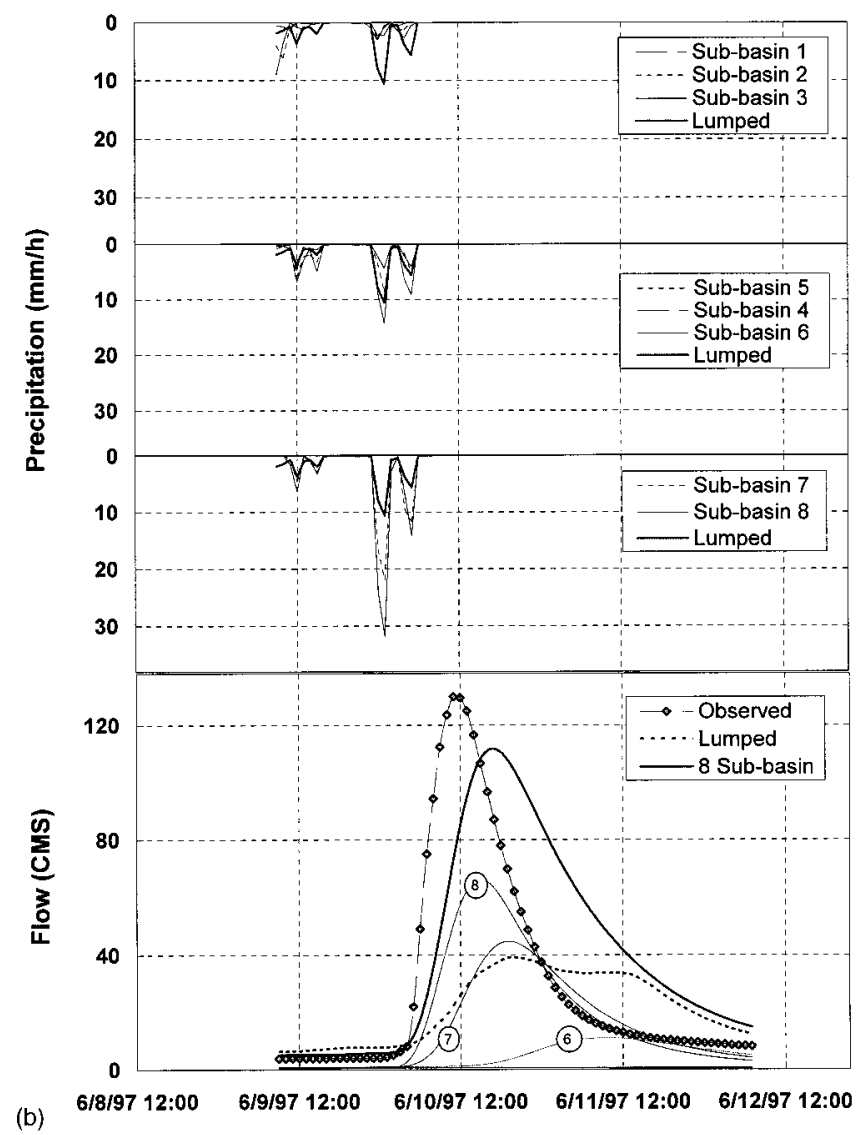

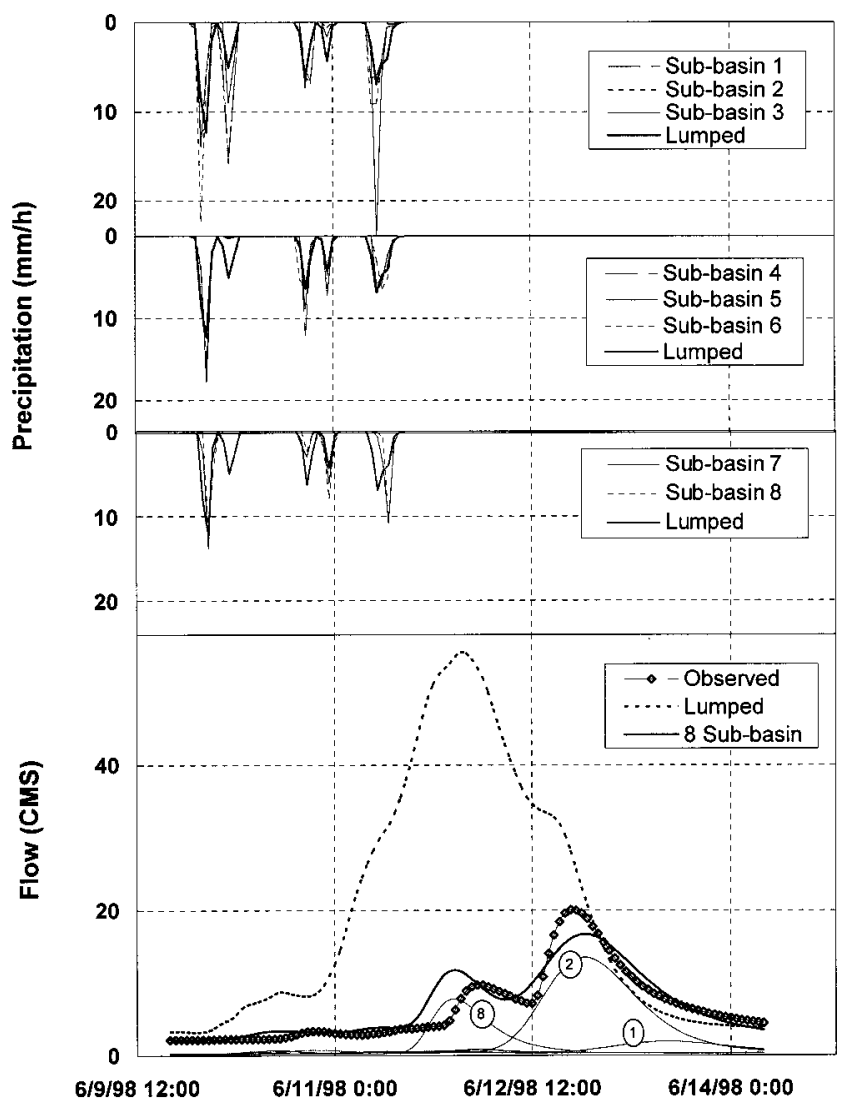

(c)

Fig. 6. Simulated and observed hydrographs and subbasin precipitation for an event (a) with a relatively uniform rainfall distribution; (b) for which rainfall was concentrated on lower subbasins; and (c) for which rainfall was concentrated on upper subbasins 
Table 4. Illustration of Benefit of Using Eight-Subbasin Model for Selected Events where Precipitation Distributions are Different

\begin{tabular}{|c|c|c|c|c|c|c|c|}
\hline \multirow[b]{2}{*}{ Event } & \multirow[b]{2}{*}{ MAPX pattern } & \multicolumn{3}{|c|}{ Eight subbasins } & \multicolumn{3}{|c|}{ Lumped } \\
\hline & & $\operatorname{Bias}(\%)$ & MAE $(\%)$ & $R$ & $\operatorname{Bias}(\%)$ & MAE $(\%)$ & $R$ \\
\hline 22:00 11/23-13:00 11/27 1996 & Relatively uniform & -3 & 21 & 0.92 & -0.4 & 20 & 0.92 \\
\hline 10:00 6/9-7:00 6/12 1997 & Concentrated on lower basins & 32 & 71 & 0.72 & -30 & 71 & 0.38 \\
\hline 19:00 6/9-6:00 6/14 1998 & Concentrated on upper basins & 7 & 18 & 0.93 & 207 & 220 & 0.23 \\
\hline
\end{tabular}

Table 5. Description of Two Tests Designed to Understand the Relative Importance of Basin Shape and Spatially Variable Rainfall-Runoff Parameters

\begin{tabular}{|c|c|}
\hline Simulations & Description \\
\hline Eight subbasins semidistributed & $\begin{array}{l}\text { Simulations are conducted based on basin disaggregation approach. The precipitation, unit } \\
\text { hydrograph, and other parameters are variable among subbasins. Calibration is conducted } \\
\text { based on soil and flow characteristics of individual subbasin. }\end{array}$ \\
\hline Test 1 & Simulations are conducted based on basin disaggregation approach. Parameters of each \\
\hline Same unit hydrograph (excludes shape factor) & $\begin{array}{l}\text { subbasin are the same as above except the unit hydrograph now is based on the calibrated } \\
\text { lumped unit hydrograph for a single basin and is adjusted according to each subbasin's } \\
\text { area. Because of usage of this hypothetical unit hydrograph, the effect of basin shape is } \\
\text { eliminated as each subbasin has the same value of time to peak. Comparison of results } \\
\text { from this test and the test described above will show the effect of excluding basin shape } \\
\text { on modeling results. }\end{array}$ \\
\hline Test 2 & This is the case where initial values of parameters for each subbasin are based on those \\
\hline $\begin{array}{l}\text { Uniformly adjusted parameters (excludes soil } \\
\text { property variation) }\end{array}$ & $\begin{array}{l}\text { from single-basin lumped calibration. The parameters are then adjusted uniformly up or } \\
\text { down across the subbasins during further calibration. Comparison of results from this test } \\
\text { and eight-subbasin test described in the first simulation case of this table will show the } \\
\text { effect of excluding variability of soil properties on the simulations. }\end{array}$ \\
\hline Single basin & $\begin{array}{l}\text { This test is conducted on a single lumped basin. It does not consider spatial variations of } \\
\text { rainfall, soil properties, and other related information. All data are basin averaged. }\end{array}$ \\
\hline
\end{tabular}

Test 2

Uniformly adjusted parameters (excludes soil property variation)

Single basin

Table 6. Yearly Comparison of Mean Absolute Error and Correlation Coefficient for Eight-Subbasin Case, Test 1, Test 2, and Lumped Case for the Blue River Basin

\begin{tabular}{|c|c|c|c|c|c|c|c|c|}
\hline \multirow[b]{2}{*}{ Year } & \multicolumn{2}{|c|}{ Eight subbasins } & \multicolumn{2}{|c|}{ Test 1 (same unit hydrograph) } & \multicolumn{2}{|c|}{ Test 2 (uniform adjustment) } & \multicolumn{2}{|c|}{ Lumped } \\
\hline & $R$ & $\operatorname{MAE}(\%)$ & $R$ & $\operatorname{MAE}(\%)$ & $R$ & MAE $(\%)$ & $R$ & MAE $(\%)$ \\
\hline 1994 & 0.86 & 45 & 0.85 & 45 & 0.87 & 41 & 0.87 & 46 \\
\hline 1995 & 0.92 & 46 & 0.89 & 46 & 0.90 & 44 & 0.86 & 45 \\
\hline 1996 & 0.90 & 37 & 0.91 & 38 & 0.89 & 46 & 0.88 & 44 \\
\hline 1997 & 0.92 & 41 & 0.90 & 48 & 0.88 & 47 & 0.87 & 46 \\
\hline 1998 & 0.95 & 31 & 0.93 & 36 & 0.94 & 39 & 0.94 & 43 \\
\hline 1999 & 0.76 & 53 & 0.66 & 61 & 0.67 & 56 & 0.56 & 59 \\
\hline Average & 0.89 & 42 & 0.86 & 46 & 0.86 & 46 & 0.83 & 47 \\
\hline
\end{tabular}

Table 7. Comparison of Peak Flow Error Among Different Simulated Cases and Observed Data for Big Events of 1994-1999

\begin{tabular}{|c|c|c|c|c|}
\hline \multirow[b]{2}{*}{ Event } & \multicolumn{4}{|c|}{ Peak flow error compared to observed $(\%)$} \\
\hline & Eight subbasins & Test 1 (same unit hydrograph) & Test 2 (uniform Adjustment) & Lumped \\
\hline 21:00 11/13/94 6:00 11/17/94 & 17.3 & 12.6 & 18.6 & 32.3 \\
\hline 23:00 5/5/95 11:00 5/11/95 & 8.9 & 7.1 & 7.0 & 18.5 \\
\hline 22:00 11/6/96 8:00 11/10/96 & 19.7 & 27.6 & 17.7 & 56.9 \\
\hline 19:00 2/19/97 4:00 2/24/97 & 8.4 & 19.3 & 8.5 & 9.6 \\
\hline 6:00 3/15/98 6:00 3/20/98 & 16.9 & 37.7 & 21.9 & 12.5 \\
\hline 7:00 4/3/99 19:00 4/5/99 & 32.9 & 46.4 & 39.5 & 67.9 \\
\hline
\end{tabular}


Table 8. Comparison of Peak Flow Error Among Selected Cases of Different Precipitation Distributions

Peak flow error compared to observed (\%)

\begin{tabular}{|c|c|c|c|c|c|}
\hline Event & MAPX pattern & Eight subbasins & Test 1 (same unit hydrograph) & Test 2 (uniform adjustment) & Lumped \\
\hline 22:00 11/23-13:00 11/27 1996 & Relatively uniform & 4 & 14 & 17 & 0.5 \\
\hline 10:00 6/9-7:00 6/12 1997 & Concentrated on lower basins & 14 & 30 & 29 & 70 \\
\hline 19:00 6/9-6:00 6/14 1998 & Concentrated on upper basins & 17 & 25 & 103 & 177 \\
\hline
\end{tabular}

\section{Comments on Calibration}

Compared to lumped calibration, calibration of multiple subbasins requires additional information to guide the adjustment of a greater number of parameters. Because each subbasin responds to rainfall (in terms of flow at the outlet) differently, by looking at individual events, one can determine which basin's parameters need to be adjusted based on rainfall pattern, moisture content in the soil, and subbasin location. For example, in the event shown in Fig. 6(b), subbasins 7 and 8 have the most precipitation during this event, and they are the closest two subbasins to the outlet. Therefore, subbasins 7 and 8 contribute most of the peak flow. By comparing the combined simulated hydrograph to the observed one and by looking at the moisture conditions for subbasins 7 and 8 , one can determine which parameter(s) for subbasins 7 and 8 need to be changed (using the same logic as in the lumped calibration). Of course, the whole simulation period should be examined for similar situations. Since changes for subbasins 7 and 8 affect only responses from the two, the hydrograph at the outlet will show improvement for those events in which subbasins 7 and 8 contribute most of the flow (usually when they have more precipitation than others). There is little or no effect on other events. In other words, this approach does not degrade the results for events where contributions are mainly from basins other than subbasins 7 and 8. So the result at the outlet after adjusting parameters for subbasins 7 and 8 usually can be improved throughout the simulation period. This might not often be the case in a
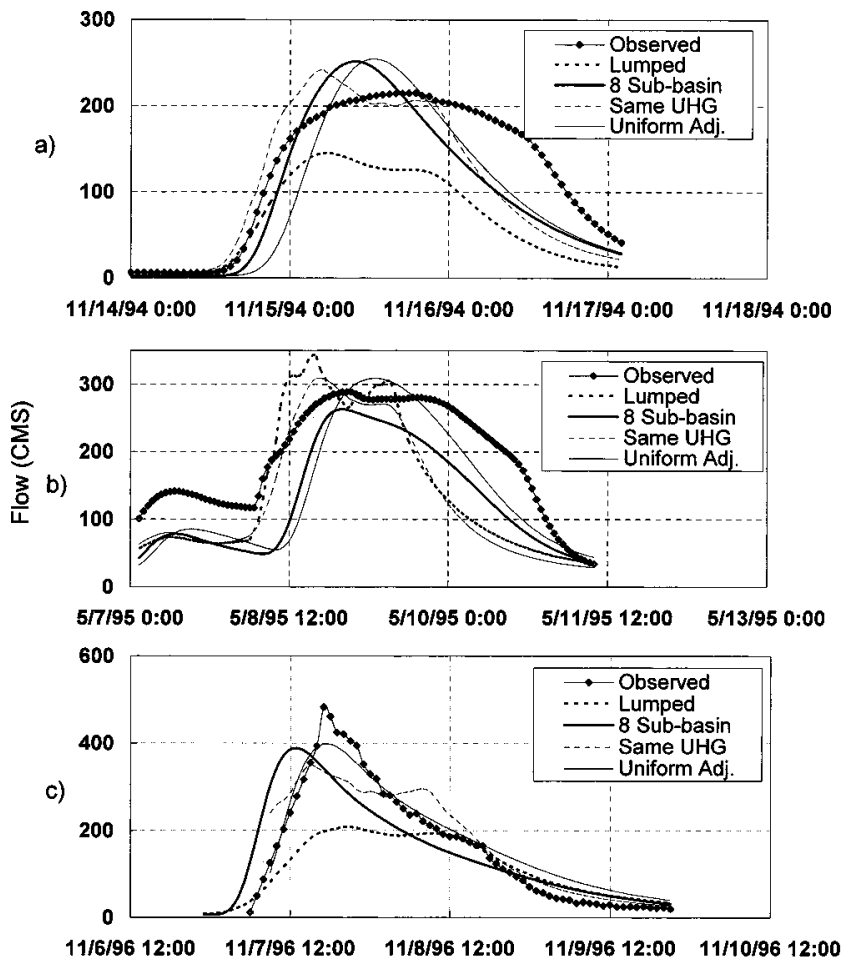

Fig. 7. Simulated and observed hydrographs for events of lumped calibration, where after adjusting a parameter the simulated result may be improved for some events while others are adversely affected. From this point of view, it may be easier to calibrate a subdivided basin than a lumped basin when the contribution of flow from each subbasin has great variation.

For the event of June 1998 [Fig. 6(c)], one can see the two peaks are mainly from responses of subbasins 8 and 2, respectively. So if there are some discrepancies between simulated and observed hydrographs, one would mainly change parameters for subbasins 8 and 2. For cases like the event in Fig. 6(a) when contributions from the subbasins are relatively even (except timing differences), one may need to adjust parameters for all subbasins uniformly up or down depending how the simulated hydrograph compares to the observed one. Alternatively, if one subbasin's hydrograph is not distributed as it should be in terms of timing and quantity when the precipitation is relatively uniform across the basin, then only that subbasin's parameters may need to be adjusted. In conclusion, the basic techniques in multiplesubbasin calibrations are similar to those in lumped calibrations except that changes are applied to specific subbasins.

\section{Discussion}

A study to compare one-basin lumped versus multiple-subbasin (through basin disaggregation) semidistributed hydrologic modeling in continuous mode has been conducted for the Blue River
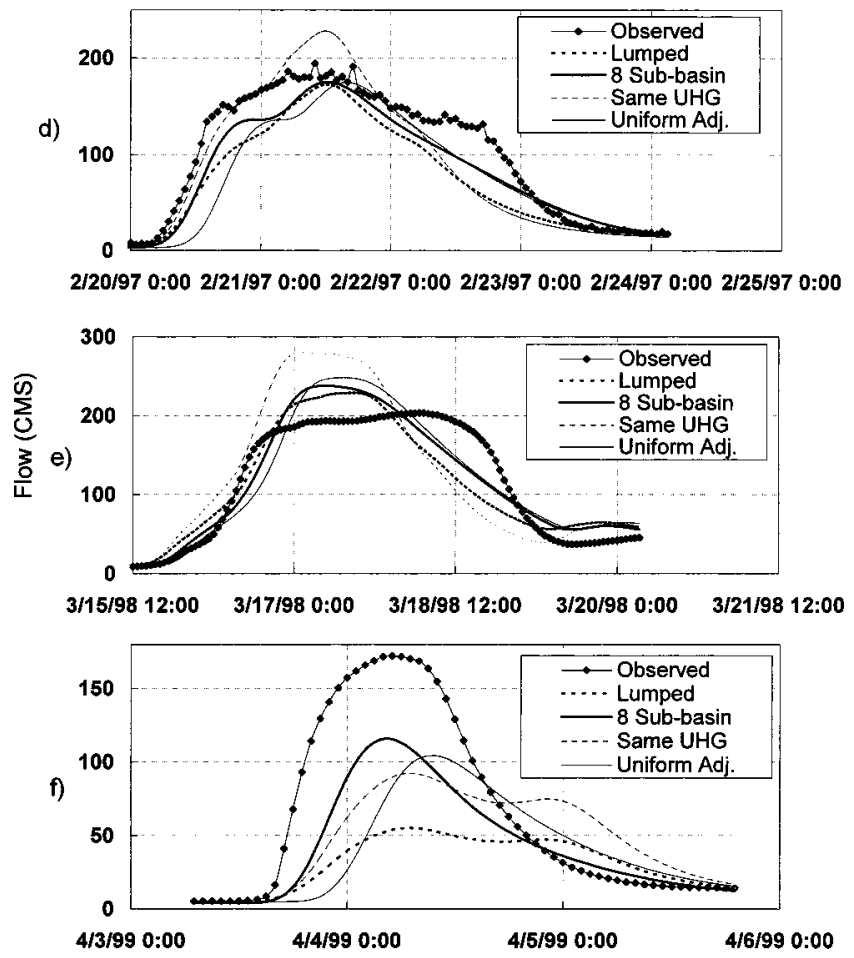

(a) 1994; (b) 1995; (c) 1996; (d) 1997; (e) 1998; and (f) 1999 
a)
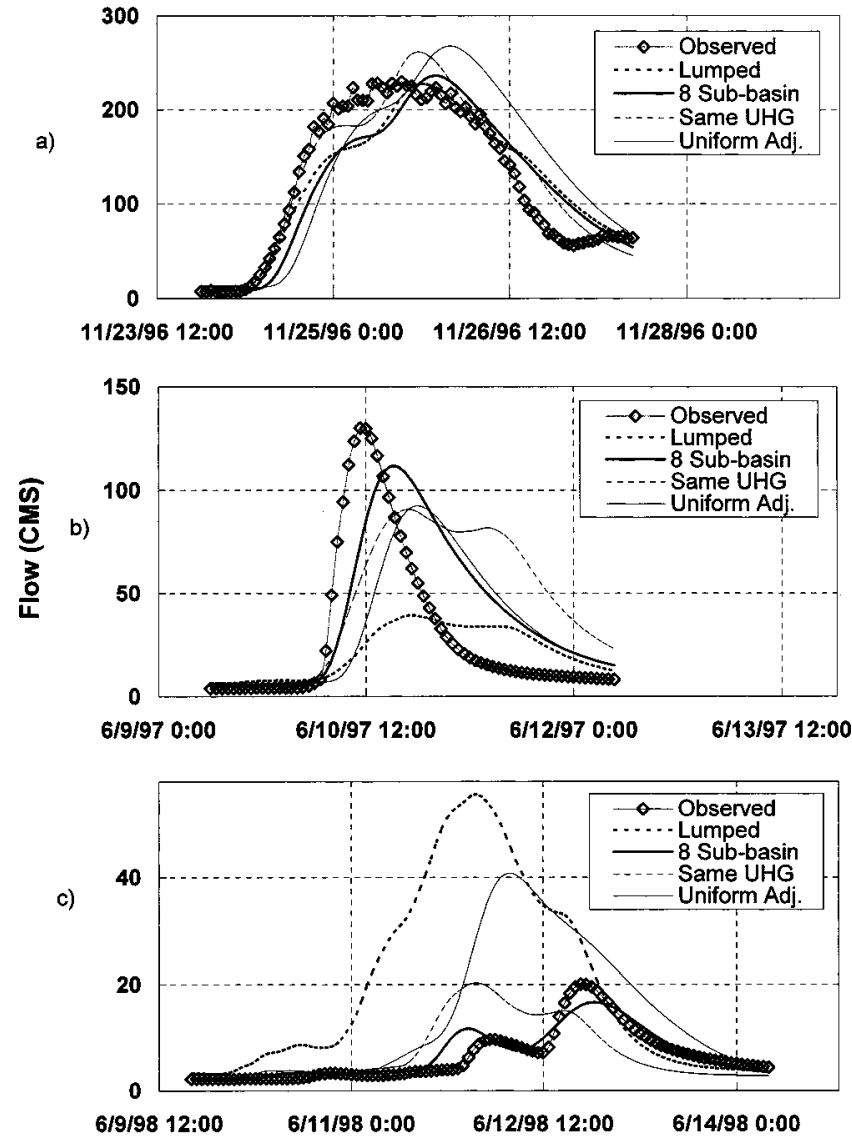

Fig. 8. Simulated and observed hydrographs for three different rainfall distribution cases

basin of Oklahoma for the time period from 1993 to 1999. This long, narrow basin has distinguishable hydrologic responses compared to other basins within the domain of ABRFC. Results based on one-basin lumped and multiple-subbasin semidistributed simulations and their comparisons to observed hydrographs are presented. Statistics and visual inspection showed that multiplesubbasin semidistributed simulations are consistently better than one-basin lumped simulations for this basin. The gain from this multiple-basin semidistributed modeling was realized primarily by accounting for the spatial variability of precipitation and soil parameters within this narrow-shaped basin. Although not used explicitly in calibration processes, soil information was used to estimate initial parameters for each subbasin and to establish a reasonable guess at spatial variability. The fact that calibrated parameters are different between subbasins is the result of spatial variability of soil, topography, and other physical characteristics within the basins. Due to a short period of radar precipitation data, an independent verification study could not be conducted.

\section{Conclusions}

Based on this study, the following conclusions can be made for the Blue River basin:

1. A subdivided model performs consistently better than a lumped model for both high- and low-flood events.

2. Tests on isolating the relative importance of accounting for basin shape and spatial variations in soil properties revealed that both factors contribute to the improvement in simulation results. Preliminary results seem to support a conclusion that accounting for basin shape and orientation has a bigger effect than soil property variability.

3. When considering storms with nonuniform rainfall, manual calibration for multiple subbasins can be easier than the lumped calibration. After initial SAC-SMA parameters are derived from the procedure described by Koren et al. (2000), visual information on the water balance and hydrographs for subbasins can help to pinpoint which subbasin's parameters need to be adjusted while minimizing adverse effects on other events or other subbasin responses.

4. The proposed strategy for calibrating multiple subbasins is similar to that for lumped calibration; however, more information needs to be examined. Additional factors to consider include precipitation distribution, soil moisture conditions for each subbasin, and location of each subbasin in relation to the basin outlet.

Our study of the Blue River shows more significant gains due to basin disaggregation. We attribute these differences to the different characteristics of the Blue River; primarily its long narrow shape and different soil characteristics. Smith et al. (1999a) did not attempt to account for SAC-SMA parameter variability among subbasins, so we cannot definitely conclude that accounting for this would not have made a difference. However, we do know that the variations in soil properties within the basins studied by Smith et al. (1999a) are less than the variations within the Blue River basin.

\section{Acknowledgments}

The writers would like to express their thanks to the USGS for providing observed discharge data and to ABRFC for providing radar precipitation data. Comments and suggestions made by Billy Olsen, Bill Lawrence, and John Schmidt at ABRFC and Dr. D. J. Seo at the Hydrology Laboratory are highly appreciated.

\section{References}

Baltas, E., and Mimikou, M. (1997). "Comparison of a lumped and a distributed flood forecasting model." Proc., Workshop/Expert Meeting on River Basin Modeling, Management and Flood Mitigation, R. Casale et al., eds., Monselice, Padua, Italy, 111-122.

Bedient, P. B., Hoblit, B. C., Gladwell, D. C., and Vieux, B. E. (2000). "NEXRAD radar for flood prediction in Houston." J. Hydrologic Eng., 5(3), 269-277.

Burnash, R. J. C., Ferral, R. L., and McGuire, R. A. (1973). "A generalized streamflow simulation system-Conceptual modeling for digital computers." Technical Rep., Joint Federal and State River Forecast Center, U.S. National Weather Service and State of California, Department of Water Resources, Sacramento, Calif.

Carpenter, T. M., and Georgakakos, K. P. (2000). "Distributed hydrologic modeling using radar precipitation." Proc., IAHS/ICRS Symposium on Remote Sensing and Hydrology 2000, M. Owe et al., eds., Publication No. 267, IAHS Press, Wallingford, Oxfordshire, U.K., 558-562.

Clark, C. O. (1945). "Storage and the unit hydrograph." Trans. Am. Soc. Civ. Eng., 110, 1419-1446.

Finnerty, B. D., Smith, M. B., Seo, D.-J., Koren, V., and Moglen, G. (1997). "Sensitivity of the Sacramento Soil Moisture Accounting Model to space-time scale precipitation inputs from NEXRAD." $J$. Hydrol., 203(1-4), 21-38.

Georgakakos, K. P., Sperfslage, J. A., and Guetter, A. K. (1996). "Operational GIS based models for NEXRAD radar data in the US." Proc., Int. Conf. Water Resources and Environmental Research, Vol. I, Water Resources Research Center, Kyoto University, Kyoto, Japan, 603609. 
Heiss, W., McGrew, D., and Sirmans, D. (1990). "NEXRAD: Next generation weather radar (WSR-88D)." Microwave J., 33, 79-98.

Johnson, B. E. (1993). "Comparison between distributed simulation versus lumped simulation in hydrologic modeling." MS thesis, Memphis State Univ., Memphis, Tenn.

Johnson, D., Smith, M., Koren, V., and Finnerty, B. (1999). “Comparing mean areal precipitation estimates from NEXRAD and rain gauge networks." J. Hydrologic Eng., 4(2), 117-124.

Koren, V., Finnerty, B. D., Schaake, J. C., Smith, M. B., Seo, D.-J., and Duan, Q.-Y. (1999). "Scale dependencies of hydrologic models to spatial variability of precipitation." J. Hydrol., 217(3-4), 285-302.

Koren, V., Smith, M., Wang, D., and Zhang, Z. (2000). "Use of soil property data in the derivation of conceptual rainfall-runoff model parameters." Proc., 15th Conf. on Hydrology, American Meteorological Society, Boston, 107-110.

Kull, D. W., and Feldman, A. D. (1998). "Evolution of Clark's unit graph method to spatially distributed runoff." J. Hydrologic Eng., 3(1), 9-19.

Miller, D. A., and White, R. A. (1998). "A continuous United States multi-layer soil characteristics data set for regional climate and hydrology modeling." Earth Interactions, 2(2), 1-26.

Mimikou, M. A., and Baltas, E. A. (1996). "Flood forecasting based on radar rainfall measurements." J. Water Resour. Plan. Manage., 122(3), 151-156.

National Weather Service (NWS). (1982). "Mean monthly, seasonal, and annual pan evaporation for the United States." NOAA Technical Rep. No. NWS 34, National Oceanic and Atmospheric Administration, U.S. Department of Commerce, Washington, D.C.

Peck, E. L. (1976). "Catchment modeling and initial parameter estimation for the National Weather Service River Forecast System." NOAA Technical Memorandum No. NWS Hydro-31, U.S. National Weather Service, National Oceanic and Atmospheric Administration, U.S. Department of Commerce, Washington, D.C.

Pessoa, M. L., Bras, R. L., and Williams, E. R. (1993). "Use of weather radar for flood forecasting in the sieve river basin: a sensitivity analysis." J. Appl. Meteorol., 32(3), 462-475.

Peters, J. C., and Easton, D. J. (1996). "Runoff simulation using radar rainfall data." Water Resour. Bull., 32(4), 753-760.

Reed, S., Koren, V., Zhang, Z., Smith, M., and Seo, D. J. (2002). "Distributed modeling for improved NWS river forecasts." Proc., 2nd Federal Interagency Hydrologic Modeling Conf., Las Vegas.

Rosso, R. (1989). "Nash model relation to Horton order ratios." Water Resour. Res., 20(7), 914-920.

Smith, M., Koren, V., Finnerty, B., and Johnson, D. (1999a). "Distributed modeling: Phase 1 results." NOAA Technical Rep. No. NWS 44, U.S.
National Weather Service, National Oceanic and Atmospheric Administration, U.S. Department of Commerce, Washington, D.C.

Smith, M., Koren, V., Zhang, Z., and Wang, D. (1999b). "Lumped and semi-distributed modeling using NEXRAD stage III data, results from continuous multi-year simulations." Proc., 1999 Georgia Water Resources Conference, Kathryn J. Hatcher, ed., Athens, Ga.

Smith, M. B., Laurine, D., Koren, V., Reed, S., and Zhang, Z. (2002). "Hydrologic model calibration in the National Weather Service." Calibration of Watershed Models, Water Science and Applications 6, Q. Duen et al., ed., American Geophysical Union, Washington, D.C., 133-152.

Stellman, K., Fuelberg, H., Garza, R., and Mullusky, M. (2000). "Investigating forecasts of streamflow utilizing radar data." Proc., 15th Conf. on Hydrology, American Meteorological Society, Boston, 115118.

University of Arizona, 1995. "1995-1996 Cooperative Agreement NA37who385." Progress Rep. prepared for Hydrologic Research Laboratory of the U.S. National Weather Service, Dept. of Hydrology and Water Resources, Tucson, Ariz.

Vieux, B. E., and Bedient, P. B. (1998). "Estimation of rainfall for flood prediction from WSR-88D reflectivity, a case study, 17-18 October 1994." Weather Forecast., 13, 407-415.

Wang, D., Smith, M. B., Zhang, Z., Reed, S., and Koren, V. (2000). "Statistical comparison of mean areal precipitation estimates from WSR-88D, operational and historical gage networks." Proc., 15th Conf. on Hydrology, American Meteorological Society, Boston, 107110.

Winchell, M., Gopta, H. V., and Sorooshian, S. (1998). "On the simulation of infiltration- and saturation-excess runoff using radar-based rainfall estimates: Effects of algorithm uncertainty and pixel aggregation." Water Resour. Res., 34(10), 2655-2670.

World Meteorological Organization (WMO). (1975). "Intercomparison of conceptual models used in operational hydrological forecasting." Operational Hydrology Rep. No. 7, Secretariat of the World Meterological Organization, WMO Publication No. 429, Geneva.

World Meteorological Organization (WMO). (1983). "Real-time data collection systems and hydrological forecasting." Proc., Technical Conf., WMO, NOAA, and the State of California Department of Water Resources, Sacramento, Calif.

Yates, D. N., Warner, T. T., and Leavesley, G. H. (2000). "Prediction of a flash flood in complex terrain, Part II: A comparison of flood discharge simulations using rainfall input from radar, a dynamic model, and an automated algorithmic system." J. Appl. Meteorol., 39, 815825. 